\title{
Effect of lubricant substances on the bond strength of relined posts to root canals
}

\author{
César Blaas Knabach, Victório Poletto-Neto, Rafael Sarkis-Onofre, Maximiliano Sérgio Cenci, \\ Tatiana Pereira-Cenci* and Rogério de Castilho Jacinto
}

*Correspondence: tatiana.dds@gmail.com.br Graduate Program in Dentistry, Federal University of Pelotas, 457 Gonçalves Chaves, Pelotas, RS CEP: 96015-560, Brazil

\begin{abstract}
The aim of this study was evaluate the influence of the substance used as root canal lubricant during relining and the cleaning protocol on the bond strength of relined posts to root dentin. Eighty single canal mandibular bovine incisors were used in the study. The root canals were endodontically treated and allocated into four groups $(n=20)$ according to the lubricant material and the root canal cleaning protocol: petroleum jelly/no cleaning; petroleum jelly/cleaning with paper points; hydrosoluble gel/no cleaning; hydrosoluble gel/water rinse and drying with paper points. All posts were relined with resin composite and luted to the root canals with regular resin cement. Specimens were cross-sectioned to obtain root slices producing $1.5 \mathrm{~mm}$ thick slices. The push-out test was performed at a crosshead speed of $0.5 \mathrm{~mm} / \mathrm{min}$ until post dislodgement occurred. The failure mode was verified using a stereomicroscope. Data were analyzed by two-way ANOVA followed by Tukey post hoc test (push-out) with $a=0.05$. A statistically significant difference was found considering the type of lubricant $(p<0.001)$. The hydrosoluble gel/water rinse group showed the highest mean bond strength value $(11.0 \pm 3.7 \mathrm{MPa})$. The most frequent pattern of failure was adhesive between the root canal walls and resin cement. The use of a hydrosoluble gel as lubricant substance seems to be adequate for the relining post technique.
\end{abstract}

Keywords: Glass, Fiber post, Resin cement, Push-out test, Relining post

\section{Background}

Glass fiber posts (GFP) were introduced in restorative dentistry as an alternative to cast metal posts, presenting good aesthetic results and better stress distribution around the dentin/resin and cement/post interface due to the similar elastic modulus of GFP and dentin [1-5]. Most failures associated to GFP are related to post debonding, especially because the adhesion to root dentin is a challenge due to control of humidity and cement/adhesive polymerization [6-8].

However, GFP do not fit well in flared canals and in this situation the layer of resin cement might be too thick, favoring the formation of air voids predisposing post debonding [9]. Impairment of mechanical properties of the tooth is another concerning issue, although there is no clearly consensus about the effect of cement thickness, attention must be given to these case scenarios, where the root canal walls are weakened due the post space preparation and endodontic treatment [10,11]. A simple solution for this issue is post relining with resin composite enhancing the adaption to the root canal

(c) The Author(s) 2016. This article is distributed under the terms of the Creative Commons Attribution 4.0 International License (http://creativecommons.org/licenses/by/4.0/), which permits unrestricted use, distribution, and reproduction in any medium, provided you give appropriate credit to the original author(s) and the source, provide a link to the Creative Commons license, and indicate if changes were made. 
walls and consequently reducing the thickness of the resin cement [12]. This technique requires the canal lubrication to allow post removal from the canal to be light cured previously to cementation [13]. Furthermore, previously to GFP cementation, the root canal should be cleaned to remove the substance used as lubricant, which could hypothetically jeopardize the adhesion of GFP to root canal dentin. Thus, it is not clear if the substance used as lubricant and the cleaning protocol of root canal walls used after this lubrication could influence the bond strength of relined posts to root dentin.

Therefore, the aim of this study was to evaluate the influence of the substance used as root canal lubricant and the cleaning protocol in the bond strength of relined posts. The null hypothesis tested was that the substance used as root canal lubricant and the cleaning protocol would have no influence on the push-out bond strength of the posts.

\section{Methods}

\section{Experimental Design}

This in vitro study has a factorial $2 \times 2$ design and assessed if lubricant material and the cleaning method could affect the bond strength of relined glass fiber posts. For this purpose, flared incisors received a relined glass fiber post and divided into four groups according to the factor lubricant (petroleum jelly or hydrosoluble gel) and the factor root canal wall cleaning protocol (with or without cleaning). Specimens were cross-sectioned to root slices to perform a push-out test, followed by a failure mode analysis.

\section{Tooth preparation}

Bovine teeth without canal calcification, open apices and curved roots were selected, cleaned with periodontal curettes (SS White, Duflex, Rio de Janeiro, Brazil) and stored in $10 \%$ formalin. The crowns were removed at $16 \mathrm{~mm}$ from the apex using slow-speed diamond disc (KG Sorensen, Barueri, Brazil) under water-cooling. The root canals were prepared by hand instrumentation using K-type files (Dentsply/Maillefer, Ballaigues, Switzerland). A crown down preparation with $1 \mathrm{~mm}$ increments was performed up to instrument size 80 . Irrigation was performed with $1 \%$ sodium hypochlorite solution after every change of file, 17\% EDTA at the finishing instrumentation and distilled water rinse. Root canal spaces were dried for $30 \mathrm{~s}$ with paper points (Tanari, Manacapuru, Amazonas, Brazil) and filled with gutta-percha and calcium hydroxide-based cement (Sealer 26; Dentsply, Konstanz, Germany) using the lateral condensation technique. The root canals were prepared for post placement removing $11 \mathrm{~mm}$ of gutta-percha using a low-speed drill (Largo n 2 , Dentsply Maillefer, Petrópolis, Rio de Janeiro, Brazil). The enlargement and regulation of the root canal walls was performed using a low speed drill from the post kit \#3 (Exacto, Angelus, Londrina, Brazil-) to create flared root canals.

\section{Lubrication and cleaning procedures}

The roots were randomly divided into four groups $(n=20)$ according to the lubricant material: petroleum jelly (Farmax, Divinópolis, Brazil) or hydrosoluble gel (KY, Johnson \& Johnson, Brazil) and root canal wall cleaning protocol was performed as following:

Group Pj Petroleum jelly applied to the root canal walls and no cleaning protocol prior the etch-and-rinse procedures of cementation. 
Group $P j+C$ Petroleum jelly applied to the root canal walls and removal of excess of lubricant using paper points prior the etch-and-rinse procedures of cementation.

Group $\mathrm{Hg}$ Hydrosoluble gel applied to root canal walls and no cleaning prior the etchand-rinse procedures of cementation.

Group $\mathrm{Hg}+\mathrm{C}$ Hydrosoluble gel applied to root canal walls, cleaning with water irrigation and drying with paper points prior the etch-and-rinse procedure of cementation.

\section{Preparation of relined posts}

Glass fiber-posts \#2 (Exacto, Angelus, Londrina, Brazil) were cleaned with ethanol for $30 \mathrm{~s}$. Silane coupling agent (Dentsply, Brazil) was applied for $60 \mathrm{~s}$ on the post using a microbrush and air-dried for $5 \mathrm{~s}$ and a small layer of adhesive (Adper Single Bond 2, 3M ESPE, Brazil) was applied in the post surface.

After the lubrication of the canals with petroleum jelly or hydrosoluble gel using a microbrush, the GFP previously prepared were covered with resin composite (Z350 XT, 3MESPE, St Paul, MN, USA) and inserted into the root canal. The resin composite was light cured for $20 \mathrm{~s}$, the relined post was removed, and then light cured (radii-cal, SDI) again for $60 \mathrm{~s}$. Next, the cleaning protocol was applied in the canals according to the previously mentioned protocol.

\section{Cementation procedure}

Dual-cured resin-based cement was used for post cementation in all groups (RelyX ARC, 3MESPE, USA). The cementation protocol was performed according the manufacturer's instructions. Briefly, each root canal wall and the relined post were etched with $35 \%$ phosphoric acid for 15 and $30 \mathrm{~s}$, respectively. The root canal walls were water rinsed and dried with paper points and the relined posts were water rinsed and air-dried. A small layer of adhesive (Adper Single Bond 2, 3MESPE, Brazil) was applied into the canal and on the relined post surface, followed by soft air-drying for $10 \mathrm{~s}$ and light cured for $10 \mathrm{~s}$ (root canal) and $40 \mathrm{~s}$ (relined post). The resin-based cement was inserted into the root canals with a Centrix syringe (DFL Indústria e Comércio SA, Brazil). The posts were seated and digital pressure was applied for $5 \mathrm{~min}$, excess cement was removed and light polymerized for $60 \mathrm{~s}$. After cementation, specimens were stored in distilled water at $37^{\circ} \mathrm{C}$ for 1 week until performed the bond strength test.

\section{Push-out test}

Roots canals were sectioned into $1.5 \mathrm{~mm}$-thick slices under water-cooling (Isomet, Buehler Ltd., Lake Bluff, IL, USA). Four slices from each root were obtained and subjected to push-out bond strength testing. The push-out load was applied using cylindrical plungers attached to a universal testing machine (EMIC DL-1000, Equipamento e Sistemas Ltd, Brazil). The tooth discs were positioned so that the load applicator tip matched with the metal base orifice and then submitted to compression loading in an apex to crown direction at a $0.5 \mathrm{~mm} / \mathrm{min}$ speed with $1000 \mathrm{~N}$ until failure by displacement of the post. Push-out bond strength was converted into megapascals (MPa) by dividing the load at failure in Newton by the bonded surface area $\left(S_{L}\right)$ in $\mathrm{mm}^{2}$, where $S_{L}$ was calculated at the lateral surface of a truncated cone using the formula: $S_{L}=\pi(R+r)\left[h^{2}+(R-r)^{2}\right]^{0,5}$, where ' $R$ ' was the coronal post radius, ' $r$ ' was the apical post radius, and ' $h$ ' was the 
thickness of the slice. The largest and smallest diameters of the anatomic post and the thickness of the slice were individually measured using a digital caliper (Series 799, Starrett, Brazil).

\section{Failure mode analysis}

The failure mode was verified by using a stereomicroscope at $40 \times$ magnification. Failures were classified into five categories: (1) adhesive between post and resin cement (no resin cement visible around the post); (2) mixed, with resin cement covering 0-50\% of the post surface; (3) mixed, with resin cement covering between 50 and $100 \%$ of the post surface; (4) adhesive between resin cement and root dentin (post enveloped by resin cement); and (5) cohesive within the resin cement [9].

\section{Statistical analysis}

The assumptions of equality of variances and normal distribution of errors were checked, and to fit these assumptions, MPa data were transformed in $\log _{10}$ and analyzed by twoway ANOVA followed by Tukey's test. Data of failure mode was analyzed by Chi square test. Data were analyzed using the Sigma Stat software v. 3.5 with $\alpha=0.05$ (Systat, Richmond, CA, USA).

\section{Results}

A statistically significant difference was found considering the type of product used as root canal lubricant ( $\mathrm{p}<0.001$, Table 1; Fig. 1). The cleaning condition and the interaction between factors did not present statistically significant differences on the bond strength. However, groups with root canal cleaning presented a 10\% higher bond strength values for hydrosoluble gel and $14.7 \%$ for petroleum jelly than groups without cleaning protocols. Figure 1 shows the bond strength results for the tested groups. The hydrosoluble gel/water rinse group presented the highest mean bond strength value $(11.0 \pm 3.7 \mathrm{MPa})$. Chi square test showed a significantly effect of tested groups on the failure modes $(\mathrm{p}<0.001)$. Table 2 shows the failure modes frequency. Groups $\mathrm{Pj}, \mathrm{Pj}+\mathrm{C}$, $\mathrm{Hg}$ and $\mathrm{Hg}+\mathrm{C}$ presented adhesive failures between root canal and resin cement respectively of $62.7,56.6,61.3$ and $31.5 \%$. The most frequent pattern obtained considering all groups was adhesive failure between the root canal and resin cement (53.2\%).

Table 1 Two-way ANOVA for bond strength values

\begin{tabular}{lcllrr}
\hline Source of variation & $\mathbf{d f}$ & Sum of squares & Mean square & F & P \\
\hline Type of product & 1 & 0.46 & 0.46 & 39.995 & $<0.001$ \\
Cleaning condition & 1 & 0.04 & 0.04 & 3.426 & 0.069 \\
Interaction & 1 & 0.00224 & 0.00224 & 0.196 & 0.659 \\
Residual & 72 & 0.82 & 0.01 & & \\
Total & 75 & 1.31 & 0.02 & & \\
\hline
\end{tabular}




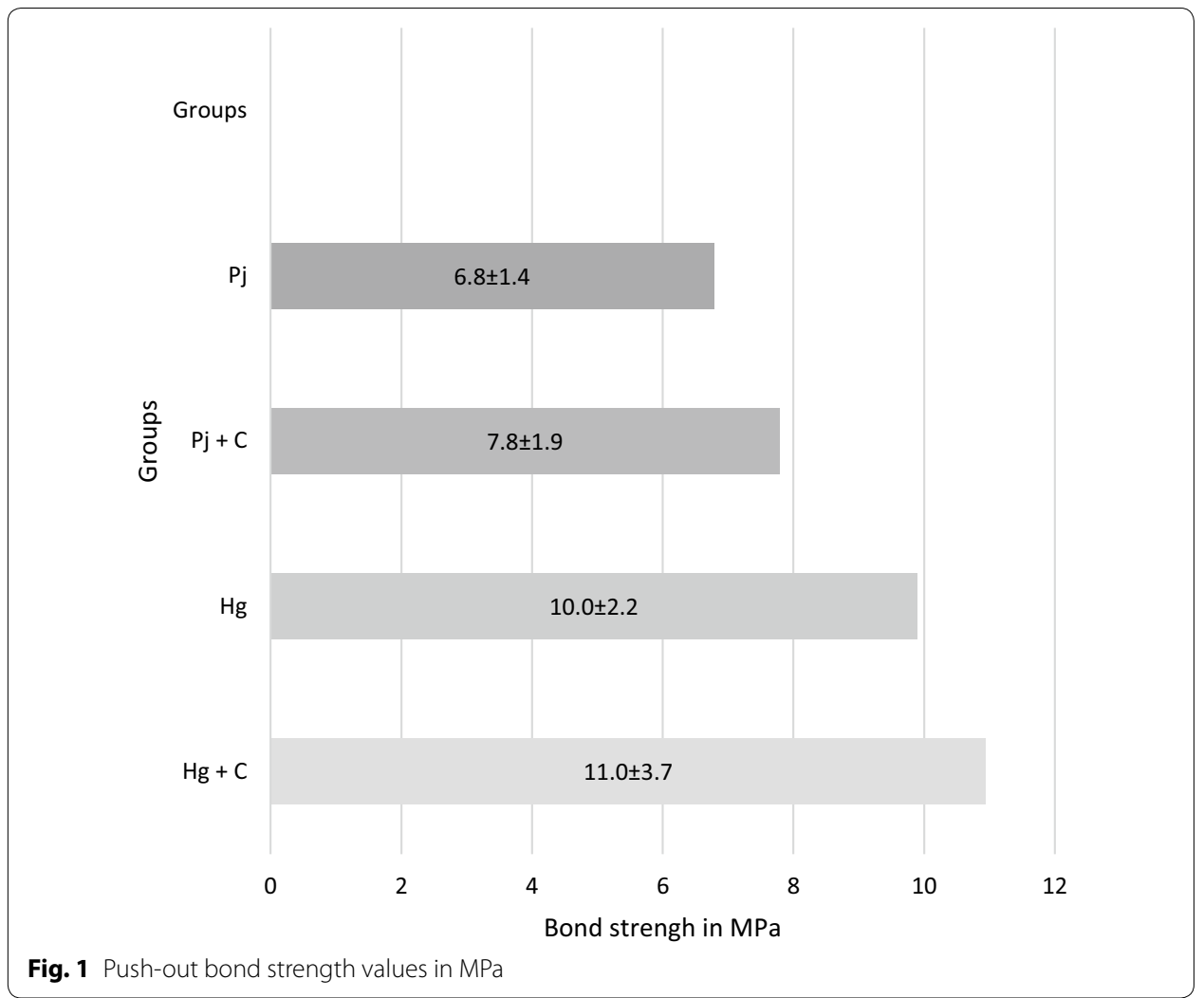

Table 2 Failure frequencies

\begin{tabular}{|c|c|c|c|c|c|c|c|}
\hline & & Type of $f a$ & ilure & & & & Total \\
\hline & & 1 & 2 & 3 & 4 & 5 & \\
\hline Petroleum jelly & Without cleaning & $1(1.3 \%)$ & $14(18.7 \%)$ & $5(6.7 \%)$ & 47 (62.7\%) & $8(10.7 \%)$ & 75 \\
\hline & With cleaning & $2(2.4 \%)$ & $23(27.7 \%)$ & $6(7.2 \%)$ & $47(56.6 \%)$ & $5(6 \%)$ & 83 \\
\hline Hydrosoluble gel & Without cleaning & $0(0 \%)$ & $20(26.7 \%)$ & $3(4 \%)$ & $46(61.3 \%)$ & $6(8 \%)$ & 75 \\
\hline & With cleaning & $7(9.6 \%)$ & $20(27.4 \%)$ & $20(27.4 \%)$ & $23(31.5 \%)$ & $3(4.1 \%)$ & 73 \\
\hline & Total & $10(3.3 \%)$ & 77 (25.2\%) & $34(11.1 \%)$ & $163(53.2 \%)$ & $22(7.2 \%)$ & 306 \\
\hline
\end{tabular}

Classification of failures: (1) adhesive between post and resin cement (no resin cement visible around the post); (2) mixed, with resin cement covering $0-50 \%$ of the post surface; (3) mixed, with resin cement covering between 50 and $100 \%$ of the post surface; (4) adhesive between resin cement and root dentin (post enveloped by resin cement); and (5) cohesive within the resin cement

\section{Discussion}

This study is the first to show that the substance used as root canal lubricant could influence the bond strength of relined posts. Our results suggest that the hydrosoluble gel is an appropriate substance to be used as lubricant in the relining post technique. This is especially important because the clinician may use hydrosoluble gel or petroleum jelly as a lubricant in clinical practice, and this choice could jeopardize the bonding procedures, leading to clinical failures, especially debonding. In addition, the cleaning protocol did not influence the bond strength results. Thus, the null hypothesis was rejected.

The substances tested in this study (petroleum jelly and hydrosoluble gel) are the most widely used substances in clinical practice when lubrication/isolation of the root canal 
walls is required. Irrespective of the cleaning condition, the hydrosoluble gel group presented higher bond strength values and this might be explained because the hydrosoluble gel can be removed from the root canal walls during the etch-and-rinse steps of the adhesive technique for post cementation. Clinicians that use petroleum jelly as lubricant material may not be aware that this product reduces (according to our study) almost 30\% of the bond strength of a cemented relined glass fiber post.

Petroleum jelly is insoluble in water and can only be dissolved with products that cannot be used into the root canal such as ether, benzene, chloroform, carbon sulfide, benzene and essence of turpentine. This is important because unlike hydrosoluble gel, the etch-and-rinse steps of the adhesive technique for post cementation is not able to completely remove the petroleum jelly remnants of the root canal walls. The use of paper points for the petroleum jelly groups seems to be insufficient to remove all the substance from the root canal walls and the use of a substance that dissolves petroleum jelly could provide higher values of bond strength, but this substance remains to be tested.

Flared canals are commonly found in the clinical practice, due to caries or endodontic procedures. This clinical condition presents a challenge to cementation of GFP. It's already stated in literature that a gap of about $50 \mu \mathrm{m}$ between post and canal walls it is recommended for a precise fit of the post to the root canals walls [14-16], since the lack of adaptation of the post could generate a thick layer of the luting agent and non-homogeneous distribution of the occlusal forces in the interface post-cement $[17,18]$, leading to lower bond strength values $[9,19,20]$.

The impairment of adhesion between dual-cured resin cements and two-step adhesive systems may occurs due the neutralization of elements responsible for chemical cure of resin cement and the difficulty of complete polymerization by the halogen light in deeper regions of canal [21-23]. Despite that, the association of RelyX Arc and Single Bond is recommended by the manufactures, and its application on GFP cementation is supported by a clinical study [24].

With regard to the failure mode analysis found in this study, the adhesive failure between resin cement and root dentin was the most frequent pattern found in all groups, corroborating previous studies $[6,25,26]$. The difference found between hydrosoluble gel groups can be a result of the cleaning protocol, since most failures occurred in the resin cement/dentin interface and only half of them occurred when a cleaning protocol was used. Type of failure is important in clinical practice [27] mainly because repair of a complete debonded relined post is simplified, only repeating the cementation procedure.

One of the limitations of present study is that only regular resin cement was tested and this could affect the results since the etch-rinse and gently drying of root canal is inherent of this technique. Knowing that this step could be suppressed in clinical practice makes the question about a cleaning protocol for root canals walls even more relevant and needed to be further improved for a better removal of the lubricant from canal walls. The comparison with self-adhesive resin cement [28] could be important since this cement does not require etch-and-rinse steps and consequently a real role of cleaning protocol could be tested in future studies. Another limitation of this study is the absence of a consolidated protocol for removal of lubricant substances from root canal walls such as petroleum jelly that is insoluble in water. 
Most of the dentists believe the acid etching process is the most effective cleaning procedure for adhesive protocols, and this seems not to be the case when petroleum jelly is used. Therefore, avoiding the use of non-hydrosoluble substances at clinical practice could help to prevent future complications such as post debonding and the use of previous removal of the lubricant followed by etch-and-rinse step seems to be enough to provide acceptable results of bond strength when using hydrosoluble gel as lubricant.

\title{
Conclusion
}

The cleaning protocols tested in this study did not promote adequate removal of petroleum jelly from root canal walls. Thus, hydrosoluble gel seems to be an appropriate substance to use as lubricant material on manufacture of relined glass fiber posts.

\author{
Abbreviations \\ Mpa: megapascal; GFP: glass fiber post.
}

\section{Authors' contributions}

CB carried out the push-out bond strength tests, participated in the data acquisition and drafted the manuscript. VPN carried out the failure mode analysis and drafted the manuscript. RSO performed the statistical analysis and drafted the manuscript. MSC participated in the design of the study, revising it critically for important intellectual content. TPC and RJC conceived of the study participated in its design and coordination and have given final approval of the version to be published. All authors read and approved the final manuscript.

\section{Acknowledgements}

The authors thank Angelus (Londrina, Brazil) for providing the glass fiber posts.

\section{Competing interests}

The authors declare that they have no competing interests.

Received: 5 October 2016 Accepted: 29 October 2016

Published online: 17 November 2016

\section{References}

1. Giachetti L, Scaminaci Russo D, Baldini M, Bertini F, Steier L, Ferrari M. Push-out strength of translucent fibre posts cemented using a dual-curing technique or a light-curing self-adhering material. Int Endod. 2012;45:249-56.

2. Stewardson DA. Non-metal post systems. Dent Update. 2001;28:326-36.

3. Silva NR, Aguiar GC, Rodrigues Mde P, Bicalho AA, Soares PB, Verissimo C, et al. Effect of resin cement porosity on retention of glass-fiber posts to root dentin: an experimental and finite element analysis. Braz Dent J. 2015;26:630-6.

4. Spazzin AO, Galafassi D, de Meira-Junior AD, Braz R, Garbin CA. Influence of post and resin cement on stress distribution of maxillary central incisors restored with direct resin composite. Oper Dent. 2009;34:223-9.

5. Soares CJ, Valdivia AD, da Silva GR, Santana FR, Menezes Mde S. Longitudinal clinical evaluation of post systems: a literature review. Braz Dent J. 2012:23:135-740.

6. Rasimick BJ, Wan J, Musikant BL, Deutsch AS. A review of failure modes in teeth restored with adhesively luted endodontic dowels. J Prosthodont. 2010;19:639-46.

7. Rezende EC, Gomes GM, Szesz AL, da Silveira Bueno CE, Reis A, Loguercio AD. Effects of dentin moisture on cementation of fiber posts to root canals. J Adhes Dent. 2016;18:29-34.

8. Skupien JA, Sarkis-Onofre R, Cenci MS, Moraes RR, Pereira-Cenci T. A systematic review of factors associated with the retention of glass fiber posts. Braz Oral Res. 2015;29:1-8.

9. Schmage P, Pfeiffer P, Pinto E, Platzer U, Nergiz I. Influence of oversized dowel space preparation on the bond strengths of FRC posts. Oper Dent. 2009;34:93-101.

10. Balkaya MC, Birdal IS. Effect of resin-based materials on fracture resistance of endodontically treated thin-walled teeth. J Prosthet Dent. 2013;109:296-303.

11. Penelas AG, Piedade VM, Borges AC, Poskus LT, da Silva EM, Guimaraes JG. Can cement film thickness influence bond strength and fracture resistance of fiber reinforced composite posts? Clin Oral Investig. 2016;20:849-55.

12. Marchi GM, Paulillo LA, Pimenta LA, De Lima FA. Effect of different filling materials in combination with intraradicular posts on the resistance to fracture of weakened roots. J Oral Rehabil. 2013;30:623-9.

13. Gomes GM, Gomes OM, Gomes JC, Loguercio AD, Calixto AL, Reis A. Evaluation of different restorative techniques for filling flared root canals: fracture resistance and bond strength after mechanical fatigue. J Adhes Dent. 2014;16:267-76.

14. Nergiz I, Schmage P, Ozcan M, Platzer U. Effect of length and diameter of tapered posts on the retention. J Ora Rehabil. 2002;29:28-34. 
15. Souza NC, Marcondes ML, Breda RV, Weber JB, Mota EG, Spohr AM. Relined fiberglass post: an ex vivo study of the resin cement thickness and dentin-resin interface. Braz Oral Res. 2016;30:1-8.

16. Souza RO, Alves ML, De Sousa RS, Dal Piva AM, Gondim LD, Ribeiro IL, et al. Resin bonding to root dentin: influence of the alveolar bone level and thickness of the cement layer. Minerva Stomatol. 2014;63:239-48.

17. Gomes GM, Rezende EC, Gomes OM, Gomes JC, Loguercio AD, Reis A. Influence of the resin cement thickness on bond strength and gap formation of fiber posts bonded to root dentin. J Adhes Dent. 2014;16:71-8.

18. Belli S, Eraslan O, Eraslan O, Eskitascioglu G. Effect of restoration technique on stress distribution in roots with flared canals: an FEA study. J Adhes Dent. 2014;16:185-91.

19. Macedo VC. Faria e Silva AL, Martins LR. Effect of cement type, relining procedure, and length of cementation on pull-out bond strength of fiber posts. J Endod. 2010;36:1543-6.

20. da Silveira-Pedrosa DM, Martins LR, Sinhoreti MA, Correr-Sobrinho L, Sousa-Neto MD, Costa EDJ, et al. Push-out bond strength of glass fiber posts cemented in weakened roots with different luting agents. J Contemp Dent Pract. 2016;17:119-24.

21. Foxton RM, Nakajima M, Tagami J, Miura H. Adhesion to root canal dentine using one and two-step adhesives with dual-cure composite core materials. J Oral Rehabil. 2005;32:97-104.

22. Pereira JR, do Valle AL, Ghizoni JS, Lorenzoni FC, Ramos MB, Dos Reis So MV. Push-out bond strengths of different dental cements used to cement glass fiber posts. J Prosthet Dent. 2013;110:134-40.

23. Mallmann A, Jacques LB, Valandro LF, Mathias P, Muench A. Microtensile bond strength of light- and self-cured adhesive systems to intraradicular dentin using a translucent fiber post. Oper Dent. 2005;30:500-6.

24. Skupien JA, Cenci MS, Opdam NJ, Kreulen CM, Huysmans MC, Pereira-Cenci T. Crown vs. composite for post-retained restorations: a randomized clinical trial. J Dent. 2016;48:34-9.

25. Faria-e-Silva AL, Pedrosa-Filho Cde F, Menezes Mde S, Silveira DM, Martins LR. Effect of relining on fiber post retention to root canal. J Appl Oral Sci. 2009;17:600-4.

26. Barfeie A, Thomas MB, Watts A, Rees J. Failure mechanisms of fibre posts: a literature review. Eur J Prosthodont Restor Dent. 2015;23:P115-27.

27. Castro CG, Santana FR, Roscoe MG, Simamoto PC Jr, Santos-Filho PC, Soares CJ. Fracture resistance and mode of failure of various types of root filled teeth. Int Endod J. 2012;45:840-7.

28. Sarkis-Onofre R, Skupien JA, Cenci MS, Moraes RR, Pereira-Cenci T. The role of resin cement on bond strength of glass-fiber posts luted into root canals: a systematic review and meta-analysis of in vitro studies. Oper Dent. 2014;39:E31-44.

\section{Submit your manuscript to a SpringerOpen ${ }^{\circ}$ journal and benefit from:}

- Convenient online submission

- Rigorous peer review

- Immediate publication on acceptance

- Open access: articles freely available online

- High visibility within the field

- Retaining the copyright to your article

Submit your next manuscript at $\boldsymbol{\nabla}$ springeropen.com 